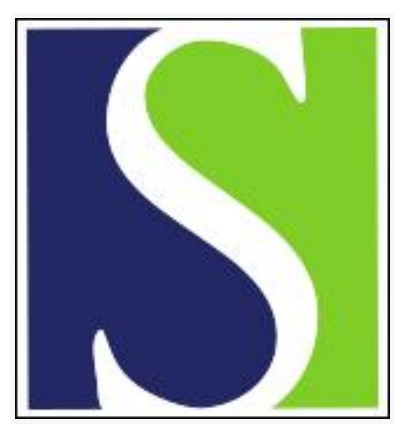

Scand J Work Environ Health 2016;42(3):251-255

https://doi.org/10.5271/sjweh.3557

Published online: 09 Mar 2016, Issue date: 01 May 2016

Methodological and conceptual issues regarding occupational psychosocial coronary heart disease epidemiology

by Burr H, Formazin M, Pohrt A

Refers to the following texts of the Journal: 2015;41(5):506-507 2015;41(6):594-596

Key terms: coronary heart disease; demand-control; demand-control model; effort-reward imbalance; epidemiology; ERI; IPD-Work Consortium; letter; methodology

This article in PubMed: www.ncbi.nlm.nih.gov/pubmed/26960179 


\section{Methodological and conceptual issues regarding occupational psychosocial coronary heart disease epidemiology}

\section{Overview}

Psychosocial occupational epidemiology has mainly focused on the demand-control and, to a much lesser extent, the effort-reward-imbalance (ERI) models. These models and the strong focus on them raise some conceptual and methodological issues we will address in the following letter.

The conceptual issues include the empirical confirmation of the assumptions of these models, the extent to which the focus on the demand-control and ERI models is warranted, and whether the sub-dimensions of the scales in these models have common health effects. We argue that there is a lack of empirical approval of (i) the assumptions behind both models and (ii) the focus on these models.

The methodological issues include how exposure to job strain is categorized, how ERI previously has been measured, and the validity of self-reports of job strain. We argue that (i) a population independent definition of job strain is lacking, (ii) the older measurements of ERI mix exposure and effect, and (iii) we know little regarding the validity of the measurement of the psychosocial working environment.

Finally, we suggest that analyses of monitoring data with a broader focus on the psychosocial working environment can be used to shed light to some of the issues raised above.

\section{Introduction}

In the last three decades $(1,2)$, psychosocial occupational epidemiology related to coronary heart disease (CHD) has mainly focused on the job-strain model, also referred to as the demand-control model $(3,4)$. In this model, two aspects of work are deemed relevant: demands and control. Negative consequences to health are to be expected when high demands are simultaneously present with low control. This combination has been termed job strain $(3,4)$. Recently, there has also been increased interest in the ERI model $(5,6)$ which considers the level of effort relative to rewards at work: an imbalance is present when the efforts outweigh the rewards $(5,6)$.
In longitudinal studies of CHD, there has been only a limited focus on investigating occupational psychosocial factors outside of these two models $(1,2)$. In this letter, we would like to raise some conceptual and methodological issues which are inherent to these two stress models but also which arise from the heavy emphasis placed on them.

\section{Conceptual issues}

The conceptual issues we discuss below are empirical confirmation of the assumptions of these models and to what extent the focus on the demand-control and ERI models is warranted.

Investigating the assumptions of the models

Both the demand-control and the ERI models are based on assumptions which have only been tested empirically to a limited extent $(1,2)$. We pose three specific questions: (i) Does the interaction of demands and control constitute a risk factor for CHD? (ii) Does the imbalance between effort and reward explain more variance in CHD risk than high effort and low reward alone? (iii) Do the sub-dimensions of the scales in these models have common health effects?

Regarding the interaction of demands and control. The concept of the demand-control model is useful when the health risk of being exposed to job strain (simultaneous high demands and low control) differs greatly from the sum of individual health risks of being exposed solely to high demands and low control. If this interaction were not present, it would be warranted to look separately at high demands and low control. This would for instance counteract overlooking those persons exposed to low control but not high demands (known as "passive work"; $3,4)$. It should be emphasized that the interaction of demands and control has only been tested in very few underpowered - cases $(1,2)$.

Initial support for an interaction within the demandcontrol model can be tentatively derived from the work of the IPD-Work Consortium (7): In a reanalysis of an earlier study (8), it was shown that while neither 
demands nor job control alone (appendix to 8) predicted CHD, job strain did when controlling for sex, age and socioeconomic status (SES) (9). This indicates that an interaction takes place. Controlling for SES is of high relevance - otherwise, the results point in a different direction (10). However, a formal test of interaction was not performed on the IPD-Work Consortium data. Even the IPD study itself might not have sufficient statistical power to analyze a possible interaction directly: this requires many more observations than simply looking at the main effects (2). If one is interested in investigating an interaction, more incident outcomes are often required (11).

Regarding effort-reward imbalance. Similarly to the combined effect of demands and control described above, focusing on the ERI model makes sense only if the imbalance of effort and reward explains the risk of CHD over and above the effect of high efforts and low rewards. To our knowledge, this has not been verified in any longitudinal study of $\operatorname{CHD}(1,2)$.

Regarding the effect of sub-dimensions. Finally, using the scales of the two models (demands and control or efforts and rewards) is meaningful only if the subdimensions of the scales all have about equal effect sizes and signs. For example, the scale psychological demands covers the sub-dimensions work pace, role conflict and work amount while control covers both influence (decision authority) and opportunities for development (skill discretion). Do these dimensions predict the risk of CHD to equal amounts within their respective scales? For now, this has not been tested elaborately to our knowledge $(1,2,12)$. Consequently, it is possible that certain risk factors in the psychosocial work environment may be overlooked due to different risk factors being merged into one scale.

\section{Is the focus on the demand-control and ERI models warranted?}

In the past, longitudinal epidemiological research on psychosocial work characteristics and their association with the risk of CHD has mainly focused on the demand-control and - to a much lesser extent - ERI models (1). For example, in a recent review (2) covering 44 papers and including 170 analyses, $70 \%$ percent of those dealt with these models or sub-dimensions thereof. Interestingly, the demand-control model alone accounted for $66 \%$ of the analyses and ERI only $4 \%$. A further $11 \%$ of the analyses dealt with working hours, $9 \%$ with social support, $5 \%$ with job insecurity, $3 \%$ with leadership and the remaining 3\% covered conflicts, justice or predictability. Maintaining the currently high degree of focus on the DC and ERI models requires evidence that job strain and ERI are by far the most important risk factors for CHD.

The review by Pejtersen et al (2) has additionally pointed out that of the 44 studies mentioned above, only two - an IPD-Work Consortium study (8) and a Swedish case-control study (13) - contained analyses with sufficient statistical power to detect an elevated CHD risk of $20 \%$. These two sufficiently powered studies available as of April 2013 have led to the following conclusions: (i) job strain was found to be predictive of CHD in the IPD-Work Consortium study (8); and (ii) both low control and low social support predicted CHD in the Swedish study (13).

Recently, a well-powered study on working hours (14) indicated that long working hours constitute a risk factor for CHD. Additionally, a recently published large study on job insecurity (15) is worth mentioning. While there was not sufficient power to detect a $20 \%$ increased risk due the relatively low prevalence of job insecurity, the study did have sufficient power to find a risk of 1.32 - which is the value actually found empirically (15).

Summarizing the small number of well-powered studies available at this time indicates that both model dimensions (job strain) as well as non-model dimensions (social support and working hours) predict CHD (8, 13-15). In this context, one should bear in mind that the variety of possible dimensions that can be considered as constituting "psychosocial work environment" is large. The latter is exemplified by a recent analysis of the psychosocial content of seven European work environment monitoring questionnaires which showed that there are 34 distinct dimensions of the psychosocial work environment (16). Around half of these dimensions are not found in either the demand-control or ERI models (16). These include for instance emotional demands, demands on hiding emotions, sensorial demands, meaning of work, commitment to the workplace, organizational influence, trust, social community at work, quality of leadership, predictability, role clarity, restructuring, safety culture, work life balance, and negative acts (eg, violence, bullying).

Little is currently known on the health effects of these "non-model" dimensions. Research on their possible effects might show that they are small - and that the DC and ERI dimensions are indeed the main psychosocial risk factors for CHD. However, results may also point to the importance of the non-model dimensions. To date, this remains to be investigated.

\section{Methodological issues}

In addition to the conceptual issues discussed above, we would like to highlight some methodological issues 
related to one or both of these models. The three main points address: (i) how exposure to job strain is categorized; (ii) how ERI has been measured up to now; and (iii) the validity of self-reports of job strain.

\section{Practical definition of job strain}

Job strain is usually operationalized as a median split of the two dimensions demands and control in the population investigated $(3,17)$. Hence, whether a certain worker experiences job strain or not depends on which other workers are part of the sample (18). This poses a problem when the distributions of demands and control differ between populations. Comparisons between Denmark and Spain and across Europe suggest that such differences exist $(19,20)$, rendering it at the least a challenge to combine populations in meta-analyses. If one assumes that the true prevalence of job strain varies between populations - based for instance on the findings just mentioned - then using population dependent medians leads to a misclassification of workers regarding their exposure to job strain. Consequently, there will be a bias to the mean in studies using the traditional job strain definition. Such misclassification and bias could also occur if demands and/or control and thus job strain change within a population over time, eg, due to an intervention.

This problem also applies to job strain based on other definitions of distributions, such as tertiles or quartiles. The seven-level definition of job strain (17) is a first step in circumventing the problem by establishing an ordinal scale of job strain; nevertheless, the levels are based on a combination of quartile-divided subgroups of the population and hence not independent from the distribution of demands and control in the sample. As long as the definition of job strain is based on the distribution of demands and control in the sample considered, the problem remains (18).

\section{Mixing exposure with effect in ERI}

In the original ERI questionnaire, workers are not solely asked about their exposure to efforts and rewards, but also whether they feel strained by this exposure (21). Hence, the ERI questionnaire to some extent also measures a stress-related reaction. Consequently, the association between measured ERI and a given outcome is not a pure measure of exposure and the outcome, but rather it contains an unknown proportion of influence due to personal characteristics. Whether a certain working condition is considered strainful to a person does not solely depend on the exposure itself but on the interplay of exposure and personal characteristics of this person. As a result, an observed association of high ERI with subsequent CHD could just as well reflect an underlying association of a stress reaction with CHD.

In the latest edition of the ERI questionnaire, the response categories have been reformulated to neutral categories. Hence, data gathered with the revised ERI will not suffer from this drawback (22). However, one has to bear the above-described effect in mind when re-analyzing existing data based on the previous ERI items.

\section{Validity of self-reported job strain}

Within the broader issue of the validity of psychosocial measures, we will focus here on one aspect, namely the validity of the assumptions underlying the DC model. This model assumes that demands and control are characteristics describing the job, not the worker (4). It is the way in which jobs are organized that determines demands and control. For example, bus drivers have less job control than truck drivers because the former group works according to a stricter schedule than the latter (4). Based on the assumption of the job strain model, one would hence expect people with exactly the same job and the same tasks to experience the same level of demands and control. With the aforementioned example, two bus drivers running the same bus line in the same city at the same hours should experience the same degree of demands and control. Whether these assumptions are warranted can for instance be derived from studies on the variance of various work characteristics explained by job titles. Such analyses indicate that a large amount of the variation of quantitative demands and control, the latter assessed as "influence at work" and "development opportunities", is indeed explained by job title (23$25)$. However, these analyses were not able to investigate the extent to which personal traits or health were biased by self-reports. To our knowledge, there are no published validation studies on the extent of selfreport bias in job strain measures due to eg, depressive symptoms or personal traits, where the study population comprised workers with exactly the same occupation and task composition. Consequently, one cannot conclude at this time that the question regarding the validity of self-reported job strain has been answered sufficiently. Carefully designed validation studies are needed in order to test specific assumptions regarding differing domains of psychosocial measures. It can be presumed that some domains more likely describe occupations and tasks (as discussed above), whereas other domains, like social support, describe more the relations among workers and management styles (26). Such validation studies could contribute to the widening of our knowledge on the validity of occupational psychosocial factors (27). 


\section{Outlook}

One could object that some of the issues we have raised here would be difficult to deal with in current research. For example, which cut-points of demands and control should one use if not the sample-based medians? Maybe here transnational data like the European Working Conditions Survey could offer such possibilities to determine externally based cut-points independent of specific samples.

A second issue is whether empirical data on nonmodel psychosocial factors are available. Currently, in many questionnaires applied in research, only the demands-control and ERI models are included. However, data collected in a more practical context like work environment monitoring offer research possibilities on non-model dimensions. As mentioned above, monitoring questionnaires cover the psychosocial work environment more broadly (16). In some European countries, monitoring data can be linked to health registers, paving the way for longitudinal studies on the association of non-model dimensions and their relations to health outcomes. As indicated above, such research will have to look at more incident precursors of manifest CHD such as prescribed hypertensive medication in order to gain sufficient statistical power (11).

In empirical research reports, there is - for formal reasons - no space for taking up issues like those we have covered here. However, we think that such issues should be raised in a more general context in the research community in order to inspire future research in the field. In this letter, we have tried to contribute to this.

\section{References}

1. Eller NH, Netterstrøm B, Gyntelberg F, Kristensen TS, Nielsen F, Steptoe A, et al. Work-related psychosocial factors and the development of ischemic heart disease: a systematic review. Cardiology in review. 2009;17(2):83-97. http://dx.doi. org/10.1097/CRD.0b013e.

2. Pejtersen JH, Burr H, Hannerz H, Fishta A, Eller NH. Update on work-related psychosocial factors and the development of ischemic heart disease: a systematic review. Cardiol Rev. 2015;23(2):94-8. http://dx.doi.org/10.1097/ CRD.0000000000000033.

3. Karasek R. Job demands, job decision latitude, and mental strain: Implications for job redesign. Administrative Science Quarterly. 1979;24:285-308. http://dx.doi. org/10.2307/2392498.

4. Karasek R, Theorell T. Healthy Work: Stress, Productivity and the Reconstruction of Working Life. New York: Basic Books; 1990.
5. Siegrist J. Adverse health effects of high-effort/low-reward conditions. Journal of Occupational Health Psychology. 1996;1:27-41. http://dx.doi.org/10.1037/1076-8998.1.1.27.

6. Siegrist J. Soziale Krisen und Gesundheit [Social crisis and health]. Göttingen: Hogrefe; 1996.

7. Kivimaki M, Kawachi I. Need for more individual-level metaanalyses in social epidemiology: example of job strain and coronary heart disease. Am J Epidemiol. 2013;177(1):1-2. http://dx.doi.org/10.1093/aje/kws407.

8. Kivimäki M, Nyberg ST, Batty GD, Fransson EI, Heikkilä $\mathrm{K}$, Alfredsson L, et al. Job strain as a risk factor for coronary heart disease: a collaborative meta-analysis of individual participant data. Lancet. 2012;380(9852):1491-7. http:// dx.doi.org/10.1016/S0140-6736(12)60994-5.

9. Kivimaki M, Nyberg ST, Kawachi I. Authors' reply: Calculation of population attributable risk should to be based on robust estimates. Scand J Work Environ Health. 2015;41(5):506-7. http://dx.doi.org/10.5271/sjweh.3518.

10. Ingre M. Excuse me, but did the IPD-work consortium just "falsify" the job-strain model? Scand J Work Environ Health. 2015;41(5):504-5.

11. Hannerz H, Dalhoff K, Burr H, Latza U. Correlation between relative rates of hospital treatment or death due to ischaemic heart disease (IHD) and of IHD-related medication among socio-occupational and economic activities groups in Denmark, 1996-2005. Int J Occup Med Environ Health. 2014;27(4):536-46. http://dx.doi.org/10.2478/s13382-0140276-6.

12. Joensuu M, Kivimaki M, Koskinen A, Kouvonen A, PulkkiRaback L, Vahtera J, et al. Differential associations of job control components with mortality: a cohort study, 19862005. Am J Epidemiol. 2012;175(7):609-19. http://dx.doi. org/10.1093/aje/kws028.

13. Hammar N, Alfredsson L, Johnson JV. Job strain, social support at work, and incidence of myocardial infarction. Occup Environ Med. 1998;55(8):548-53. http://dx.doi. org/10.1136/oem.55.8.548.

14. Kivimaki M, Jokela M, Nyberg ST, Singh-Manoux A, Fransson EI, Alfredsson L, et al. Long working hours and risk of coronary heart disease and stroke: a systematic review and meta-analysis of published and unpublished data for 603838 individuals. Lancet. 2015 Oct 31;386(10005):1739-46.

15. Virtanen M, Nyberg ST, Batty GD, Jokela M, Heikkila K, Fransson EI, et al. Perceived job insecurity as a risk factor for incident coronary heart disease: systematic review and metaanalysis. BMJ (Clinical research ed). 2013;347:f4746. http:// dx.doi.org/10.1136/bmj.f4746.

16. Formazin M, Burr H, Aagestad C, Tynes T, Thorsen SV, Perkio-Makela M, et al. Dimensional comparability of psychosocial working conditions as covered in European monitoring questionnaires. BMC Public Health. 2014;14:1251. http://dx.doi.org/10.1186/1471-2458-14-1251.

17. Karasek R, Choi B, Ostergren PO, Ferrario M, De Smet P. Testing two methods to create comparable scale scores between the Job Content Questionnaire (JCQ) and JCQ-like questionnaires in the European JACE study. International 
Journal of Behavioral Medicine. 2007;14:189-201. http:// dx.doi.org/10.1007/BF03002993.

18. Smith PM, LaMontagne AD. What is needed to make research on the psychosocial work environment and health more meaningful? Reflections and missed opportunities in IPD debates. Scand J Work Environ Health. 2015 Nov;41(6):594 6. http://dx.doi.org/10.5271/sjweh.3519.

19. Moncada S, Pejtersen JH, Navarro A, Llorens C, Burr H, Hasle $\mathrm{P}$, et al. Psychosocial work environment and its association with socioeconomic status. A comparison of Spain and Denmark. Scand J Public Health. 2010;38(3 Suppl):137-48. http://dx.doi.org/10.1177/1403494809353825.

20. Holman D. Job types and job quality in Europe. Human Relations. 2013;66(5):475-502. http://dx.doi. org/10.1177/0018726712456407.

21. Siegrist J, Starke D, Chandola T, Godin I, Marmot M, Niedhammer I, et al. The measurement of effort-reward imbalance at work: European comparisons. Soc Sci Med. 2004;58(8):1483-99. http://dx.doi.org/10.1016/S02779536(03)00351-4.

22. Siegrist J, Li J, Montano D. Psychometric properties of the Effort-Reward Imbalance Questionnaire. Düsseldorf, Germany: Department of Medical Sociology, Faculty of Medicine, Düsseldorf University; 2014. Available from: http://www.uniklinik-duesseldorf.de/fileadmin/Datenpool/ einrichtungen/institut_fuer_medizinische_soziologie_id54/ ERI/PsychometricProperties.pdf [Retrieved 2015 Sep 18th].

23. Bültmann U, Kant I, van Amelsvoort LG, van den Brandt PA, Kasl SV. Differences in fatigue and psychological distress across occupations: results from the Maastricht Cohort Study of Fatigue at Work. J Occup Environ Med. 2001 Nov;43(11):976-83. http://dx.doi.org/10.1097/00043764200111000-00008
24. Fredlund P, Hallqvist J, Diderichsen F. Psykosocial exponeringsmatris. En uppdatering av ett klassifikationssystem för yrkesrelaterade psykosociala exponeringar [Psychosocial job exposure matrix. An update of a classification system for work-related psychosocial exposures]. Stockholm: National Institute for working life; 2000.

25. Schwartz JE, Pieper CF, Karasek RA. A procedure for linking psychosocial job characteristics data to health surveys. Am J Public Health. 1988;78(8):904-9. http://dx.doi.org/10.2105/ AJPH.78.8.904.

26. Pejtersen JH, Kristensen TS, Borg V, Bjorner JB. The second version of the Copenhagen Psychosocial Questionnaire. Scandinavian Journal of Public Health. 2010;38:8-24. http:/ dx.doi.org/10.1177/1403494809349858.

27. Rugulies R. Studying the effect of the psychosocial work environment on risk of ill-health: towards a more comprehensive assessment of working conditions. Scand J Work Environ Health. 2012;38(3):187-91. http://dx.doi. org/10.5271/sjweh.3296.

Received for publication: 5 October 2015

Hermann Burr, PhD, ${ }^{1}$ Maren Formazin, PhD, ${ }^{1}$ Anne Pohrt, MSc ${ }^{1}$

${ }^{1}$ Federal Institute for Occupational Safety and Health (BAuA), Nöldnerstraße 40-42, 10317 Berlin, Germany.

Correspondence to: Hermann Burr, Federal Institute for Occupational Safety and Health (BAuA), Nöldnerstraße 40-42, 10317 Berlin, Germany. [E-mail: burr.hermann@ baua.bund.de] 